\title{
HOW ORDINARY CITY SHIFT TO SMART CITY? A CASE STUDY "CITIZEN-CENTERED"
}

\author{
Hosni Seffih ${ }^{1,2}$, Myriam Lamolle ${ }^{1}$, Aurélie Pradelles ${ }^{2}$, Ayoub Chouchou ${ }^{3}$ and Christian Fluhr ${ }^{2}$ \\ ${ }^{1}$ LIASD-EA4383, IUT de Montreuil, Univ. Paris 8, 140 rue de la Nouvelle France 93100 Montreuil, France \\ ${ }^{2}$ Geolsemantics, 12, avenue Raspail 94250 Gentilly, France \\ ${ }^{3}$ Transfero, 39, cite Mayen Djeloul, 19000, Setif, Algeria.
}

\begin{abstract}
The Smart City concept is a very recent one, which, nevertheless, has already implemented in several cities around the world (for example, Dubai, Moscow, Paris). The satisfactory results are encouraging more and more cities to experiment with this concept; given that the normal city of the future will be the smart city, regardless of its size and location. We have noticed during November 2018 Sétif start-ups fair, in Algeria, the strong desire of local authorities and investors to shift to a smart management of their city (Elmoudjahid, 2019). In this article we will study the transition of an ordinary city into a smart city, whatever its socio-economic environment. The concept of a smart city will be presented, in the first instance, then we will examine various examples of cities in view of transitioning to smart city, so as to propose an application at low-cost based essentially on the collaboration of the inhabitants (which we will call "smart Citizen-centred city"), this way we will pass over the lack of developed systems benefitting from open data, sensor networks, etc. Because of this, we have selected the theme "intelligent transport", presenting a simple transport application in the Wilaya of Sétif, which will depend on the connected people.
\end{abstract}

\section{KEYWORDS}

Smart city, Smart Transport, Smart Community, NLP, Data-Mining

\section{INTRODUCTION}

Since its conception, the idea of a "smart city" has evolved, going from the execution of specific projects to the implementation of global strategies with a view to facing the cities' greatest challenges. It is therefore necessary to obtain a view of all the available possibilities and to relate them to specific challenges. A smart city is representative of the innovation of the running of the city, its services and its infrastructure. A common definition of the term has not yet been decided (O'Grady and O'Hare, 2012).

We note that the smart city concept has emerged within the last 20 years, whether in scientific writing or in political discourse. The city has a big social, economic and environmental imprint (Mori and Christodoulu, 2012). According to (UN 2008), more than 50\% of the world's population live in an urban environment. That is expected to reach $75 \%$ in 2050. According to the same report, cities consume between 60 and $80 \%$ of the world's resources.

According to (Turcu 2013; Berardi 2013a; 2013b), cities should respond to the needs of their inhabitants by finding durable solutions. The smart city concept is not just limited to the application of new technologies to the running of a city, but also is linked to the concept of the sustainable city.

As stated before there are many definitions of the concept of the smart city and even more if we topple the adjective "smart" in favour of "digital" or "intelligent". The term was used for the first time in the 1990s; at that time, studies focused on information and communication technology (ICT) and its impact on modern infrastructure in cities.

According to (Harrison et al. 2010), the term "smart city" applies to the cities that can capture and integrate data in real time using sensors, meters, domestic appliances, interconnected personal appliances, etc. The term "intelligent" refers to analysis, modelling, optimisation of resulting data to aid decision taking. 
For (Ballas, 2013), the term "smart city" refers to governmental politics, which place upon "intelligent" strategies, to achieve sustainable development, an economic development and a better quality of life for citizens (Albino et al, 2015).

We can deduct from these definitions that the concept of a smart city implicates an approach for the management and development of the city that can be used globally. These definitions show a balance of technological, economic and social factors put in place within an urban ecosystem. These definitions reflect a global approach to urban problems taking part in new technologies to redefine the urban model and the relationships between the parties involved (Caragliu, Del Bo and Nijkamp 2009; Harrison et al, 2010; Correia et al, 2011; Nam and Pardo, 2011; Batty et al, 2012 and UN-HABITAT, 2015).

However, it can be pointed out that infrastructure is a central element of the smart city and technology is the catalyst which allows it, combining the two is fundamental to the transition of the ordinary city to smart city (Nam and Pardo, 2011).

\section{RELATED WORKS}

Many research projects have worked on the question of how to transform an ordinary city into a smart city or how to have a smart management in the city, which includes a smart economy, a smart environment, smart transport, etc, (Advancity et al, 2016) whether within cities which already have a smart infrastructure and management, which we will call the "northern cities", or whether they be the cities which have started to test certain concepts of smart management, which we will call the "southern cities".

For example, in Casablanca, (Safia et al, 2018), with the use of Geographical Information Systems sensors, present their approach to plan the distribution of food products from a single depot to multiple customers with variable demand rates, beginning by collecting data to model the problem of directing their heavy goods vehicles. Through this approach, they have presented the real-life case of a distribution firm in the food sector in a southern country using a multi-channel distribution circuit. The objective of this case study is to select the optimal configuration to satisfy clients, reduce business costs and avoid congestion in the city. In Algeria, an ontological solution has been developed to economise on energy thanks to a smart home in the city of Adrar (Boudaa et al, 2018). Using a Natural Language Processing (NLP) tool (Namiot et al, 2018), have tried to progress towards smart transport. The objective is to model the journeys of passengers and to create a pattern using the model of social and economic behaviour of residents in the Russian capital Moscow.

Studies on the concept of smart city itself have been carried out, as with ASCIMER (Monzon, 2015), a project developed by the Universidad Politecnica of Madrid (UPM) for the EIBURS call on "Smart City Development: Applying European and International Experience to the Mediterranean Region" The stated objectives were:

- To define the concept of the smart city and understand how it could contribute to the achievement of priorities for urban development.

- To develop a methodology to evaluate and prioritise Smart City projects.

- To elaborate guidelines for the implementation and direction of Smart City projects.

- To characterise the challenges of Mediterranean cities and develop a transitional strategy for Smart City projects.

The cities considered as belonging to the North Mediterranean Region are those located in countries of the European Union. The countries in the South and East Mediterranean region that have been considered in the study are: Morocco, Algeria, Tunisia, Libya, Egypt, Jordan, Israel, Lebanon, Syria and Turkey. It is imperative to study the applicability of the concept in all these regions, and to have a history of places where this has succeeded.

In all the preceding examples, a certain level of technology is necessary (for example, a network of GIS sensors, a well-defined terminology of the places in the case of Moscow), but this is not necessarily available. In the case of transport networks, many cities do not have the technology for sensors, or for machine validation of tickets, or standardised linguistic terminology for the referencing of locations. 


\section{CASE STUDY}

At the centre of the Hautes Plaines region in the east of Algeria, the city of Sétif benefits from a strategic positioning in a traffic network, which has been reinforced, in recent years, by the doubling of all national routes and the implementation of the east-west route. With more than 300,000 inhabitants in the capital city and more than 400,000 inhabitants in the urban area, Sétif constitutes an important human concentration, a very attractive place for its activities, its production of services and its potential for development due mainly to its accessibility (Kebiche, 2017). The expansion of the city of Sétif is characterised by the phenomenon of the "urban transition" (WIEL M, 1999), the urban transition or the shift from the pedestrianised to the motorised city.

Knowing that we have at our disposal the database of all the stations in the city of Sétif, we will create a "smart citizen-centred transport" application, it's a small urban parc with 350 operators, 15 lines and 426 vehicles in $2015^{1}$. The principal objective is the participation of users to report the progression of buses from one station to the other and send alerts in the event of any bus failure. The collaborative area must take into consideration the fact that the stations referenced in the database for the city of Sétif do not necessarily correspond with the names given in "street vocabulary". Timetables are therefore calculated step by step by the signals from inhabitants while considering the adaptation to the vocabulary.

To do this, the calculation of times requires a data-mining module based on the users' reports. The adaptation of vocabulary is made by a module of natural language processing (NLP) to complete the dictionary of different names given to different places.

We hope that during the use of this application, the relevance of the developed timetables will be closer and closer to reality, bringing more and more residents to use public transport.

\subsection{Datamining Module}

Once the application is propagated, we will carry out a data-mining operation on the data sent by the users, by using an unsupervised learning algorithm coupled with a Bayesian inference. We will be able to identify the location of means of transport in real time and estimate the time in which it will reach the next station. The data sent by the user can be the GPS coordinates, but if there is only a declaration of place from the user, we will apply a comment section this is will allow users to declare events and places on what's holding the traffic, of course the GPS will not be always enabled. Therefore, we will have to extract the place from the comment, even if we will have to deal with many problems like fake notifications, a problem that has both manual and automatic solutions, we can start by allowing other users that are in the same area to confirm the event, and then we using those confirmation we can build a model and use machine learning to predict future fake notifications (Guibon et al, 2019), it will be necessary to identify the place and collect its coordinates. For this, we will have need of an NLP module.

\subsection{Natural Language Processing (NLP)}

The automatic treatment of the natural language will be a great help to us in this context. We are confronted with two challenges: the first being the identification of location, as the users tend to name places differently to their official name, whether by the old name of the street, abbreviated name or in slang (e.g. Dallas (common name) -> Cité du 1 Novembre (official name)). It is therefore necessary to create a dictionary of the different names given to a place. The other challenge is that names can be written in different ways: phonetic spelling, reversing letters, etc. Because of this, we will install a spell checker to propose corrections (e.g. telefone -> telephone) or try different linguistic methods to suggest the appropriate spelling to the user.

It is necessary to use an NLP module for places recognition inside users' notifications, especially when it concerns names not containing proper nouns. It may then be interesting to mix the NLP module with GPS information when it is accessible, in order to be sure to link the official name of the stop with the one used by users.

\footnotetext{
${ }^{1}$ Source : ONTA organisation nationale des transporteurs algériens, 2015
} 


\section{CONCLUSION}

A successful smart transport network can constitute a gateway to other domains that will appear in a smart city. Each region presents different challenges. In our case study, we will have to overcome the absence of databases and GPS tool based, by relying on a collaborative system, in the same manner as Waze. The NLP will help us to position the means of transport and above all to predict the time of passage at each station and the best itinerary for the user. We will also try to resolve the problem of places naming, and deal with the difference between official names and the names more commonly used by the public for the same place; a disambiguation which will surely aid those passing through Sétif. Later, the user will also be able to announce an incident, her/his text will immediately be analysed and serve to create an alert.

It remains to be seen if citizens will be receptive and will permit the development of this application. Up until now we have seen encouraging results with Yassir and Jumia which have respectively added a model akin to Uber and to Amazon on the Algerian market, solving in an elaborate way the problem of the lack of online payment methods in Algeria. Of course, we will have to deal with the problem of how to make our app viral, advertising around the stations and the buses will be our first stage, this should help us build a community we will then have to find ways to make this community active, this will be discussed in our next article.

\section{REFERENCES}

Elmoudjahid, 2019. Le salon de l'emploi et des start-ups s'ouvre aujourd'hui à Sétif. [online] Available at: http://www.elmoudjahid.com/fr/actualites/130889 [Accessed 27 Mar. 2019].

O'Grady, M. and O'Hare, G., 2012. How smart is your city? Science, 335(6076), pp. 1581-1582.

Mori, K. and Christodoulou, A., 2012. Review of sustainability indices and indicators: Towards a new City Sustainability Index (CSI). Environmental impact assessment review, 32(1), pp. 94-106.

UN, United Nations, 2008. World Urbanization Prospects: The 2007 Revision Population Database. United Nations

Turcu, C., 2013. Re-thinking sustainability indicators: local perspectives of urban sustainability. Journal of Environmental Planning and Management, 56(5), pp. 695-719.

Berardi, U., 2013a. Clarifying the new interpretations of the concept of sustainable building. Sustainable Cities and Society, 8, pp. 72-78.

Berardi, U., 2013b. Sustainability assessment of urban communities through rating systems. Environment, development and sustainability, 15(6), pp. 1573-1591.

Harrison, C., Eckman, B., Hamilton, R., Hartswick, P., Kalagnanam, J., Paraszczak, J. and Williams, P., 2010. Foundations for smarter cities. IBM Journal of Research and Development, 54(4), pp.1-16.

Ballas, D., 2013. What makes a 'happy city'? Cities, 32, pp. S39-S50.

Albino, V., Berardi, U. and Dangelico, R.M., 2015. Smart cities: Definitions, dimensions, performance, and initiatives. Journal of Urban Technology, 22(1), pp. 3-21.

Caragliu, A., Del Bo, C. and Nijkamp, P., 2009. Smart Cities in Europe. 3rd Central European Conference in Regional Science-CERS. Slovakia.

Correia, L.M. and Wünstel, K., 2011. Smart cities applications and requirements. White Paper. Net!Works European Technology Platform.

Nam, T. and Pardo, T.A., 2011. Conceptualizing smart city with dimensions of technology, people, and institutions. In Proceedings of the 12th annual international digital government research conference: digital government innovation in challenging times pp. 282-291. ACM.

Batty, M., Axhausen, K.W., Giannotti, F., Pozdnoukhov, A., Bazzani, A., Wachowicz, M., Ouzounis, G. and Portugali, Y., 2012. Smart cities of the future. The European Physical Journal Special Topics, 214(1), pp.481-518.

UN-HABITAT, 2015. The state of African cities 2014: Re-imagining sustainable urban transitions. United Nations Human Settlements Programme. UN-Habitat.

Advancity, Cap-digital, and systematic, 2016. Livre Blanc "Le Numérique Et La Ville". [online] Available at: https://systematic-paris-region.org/wp-content/uploads/2017/05/LIVRE-BLANC-2016-Le-numérique-et-la-ville.pdf [Accessed 27 Mar. 2019].

Safia, L., Jamal, B., Mustapha, A., Salma, M. and Sabry, A.H., 2018. Optimization of Vehicle Routing for Smart City: Real Case Study in Casablanca. Smart Application and Data Analysis for Smart Cities (SADASC'18). Casablanca, Morocco. 
Boudaa, B., Hammoudi, S. and Benslimane, S.M., 2018. Towards an extensible context model for mobile user in smart cities. In Computational Intelligence and Its Applications: 6th IFIP TC 5 International Conference, CIIA 2018, Oran, Algeria, May 8-10, 2018, Proceedings 6 (pp. 498-508). Springer International Publishing.

Namiot, D., Pokusaev, O. and Kupriyanovsky, V., Data Mining on the Use of Railway Stations. [online] Available at: http://ceur-ws.org/Vol-2268/paper7.pdf [Accessed 27 Mar. 2019].

Monzon, A., 2015. Smart cities concept and challenges: Bases for the assessment of smart city projects. In Smart Cities and Green ICT Systems (SMARTGREENS), 2015 International Conference. Lisboa, Portugal. pp. 1-11. IEEE.

KEBICHE A., 2017. Le tramway de SETIF: une opportunité d'articuler urbanisme et mobilité pour un «projet de ville». Cahiers Géographiques de l'Ouest, $\mathrm{n}^{\circ} 12-13,2017$.

Wiel M., 1999. La Transition urbaine: ou le passage de la ville pédestre à la ville motorisée. Editions Mardaga. Belgique.

Guibon G, Ermakova L, Seffih H, Firsov A and Le Noé-Bienvenu G., 2019. Multilingual Fake News Detection with Satire on Vaccination Topic. Conference on Computational Linguistics and Intelligent Text Processing Cicling 2019. La Rochelle, France 